\title{
Pharmacokinetics of HIV-Integrase Inhibitors During Pregnancy: Mechanisms, Clinical Implications and Knowledge Gaps
}

\author{
Ruben van der Galiën ${ }^{1} \cdot$ Rob ter Heine $^{1} \cdot$ Rick Greupink $^{2}$ - Stein J. Schalkwijk ${ }^{1,2}$ • \\ Antonius E. van Herwaarden ${ }^{3}$ - Angela Colbers ${ }^{1} \cdot$ David M. Burger $^{1}$
}

Published online: 19 June 2018

(C) The Author(s) 2018

\begin{abstract}
Prevention of mother-to-child transmission of HIV and optimal maternal treatment are the most important goals of antiretroviral therapy in pregnant women with HIV. These goals may be at risk due to possible reduced exposure during pregnancy caused by physiological changes. Limited information is available on the impact of these physiological changes. This is especially true for HIV-integrase inhibitors, a relatively new class of drugs, recommended first-line agents and hence used by a large proportion of HIV-infected patients. Therefore, the objective of this review is to provide a detailed overview of the pharmacokinetics of HIV-integrase inhibitors in pregnancy. Second, this review defines potential causes for the change in pharmacokinetics of HIV-integrase inhibitors during pregnancy. Despite increased clearance, for raltegravir $400 \mathrm{mg}$ twice daily and dolutegravir $50 \mathrm{mg}$ once daily, exposure during pregnancy seems adequate; however, for elvitegravir, the proposed minimal effective concentration is not reached during pregnancy. Lower exposure to these drugs may be caused by increased hormone levels and, subsequently, enhanced drug metabolism during pregnancy. The pharmacokinetics of bictegravir and cabotegravir, which are under development, have not yet
\end{abstract}

David M. Burger

David.Burger@radboudumc.nl

1 Department of Pharmacy, Radboud Institute of Health Sciences, Radboud University Medical Center, Geert Grooteplein Zuid 10, 6525 GA Nijmegen, The Netherlands

2 Department of Pharmacology and Toxicology, Radboud Institute of Molecular Life Sciences, Radboud University Medical Center, Nijmegen, The Netherlands

3 Department of Laboratory Medicine, Radboud Institute of Molecular Life Sciences, Radboud University Medical Center, Nijmegen, The Netherlands been evaluated in pregnant women. New studies need to prospectively assess whether adequate exposure is reached in pregnant women using these new HIV-integrase inhibitors. To further optimize antiretroviral treatment in pregnant women, studies need to unravel the underlying mechanisms behind the changes in the pharmacokinetics of HIV-integrase inhibitors during pregnancy. More knowledge on altered pharmacokinetics during pregnancy and the underlying mechanisms contribute to the development of effective and safe antiretroviral therapy for HIV-infected pregnant women.

\section{Key Points}

Pregnancy leads to a reduction in pharmacokinetic exposure to HIV-integrase inhibitors, which may endanger viral suppression. Not all mechanisms behind the changes in the pharmacokinetics of HIVintegrase inhibitors during pregnancy are known and we need to unravel these to optimize antiretroviral therapy during pregnancy.

More knowledge on the changes in the pharmacokinetics of HIV-integrase inhibitors during pregnancy may further facilitate and guide the development of effective and safe treatment of HIVinfected pregnant women. 


\section{Introduction}

Physiological changes occurring during pregnancy affect exposure to drugs. In particular, for newly developed antiretroviral drugs such as HIV-integrase inhibitors, knowledge gaps exist on the clinical relevance of the altered pharmacokinetics, and also which physiological changes mainly drive the altered exposure of HIV-integrase inhibitors. HIV-integrase inhibitors have achieved high rates of virologic suppression, as shown in large clinical trials and in clinical practice, and often have greater tolerability than protease inhibitor (PI)- or nonnucleoside reverse-transcriptase inhibitor (NNRTI)-based regimens [1,2]. This led to the Department of Health and Human Services (DHHS) guidelines recommending HIVintegrase inhibitor-based regimens as initial therapy for most people with HIV, over NNRTI or PI regimens [2], and explains the large proportion of HIV-infected patients using these agents [3-6]. The HIV-integrase inhibitors raltegravir, dolutegravir and elvitegravir, the latter boosted with cobicistat, have been approved in the Western world, while the newest agents cabotegravir and bictegravir are currently under clinical development. Because of accumulating experience, as well as knowledge on efficacy, pharmacokinetics and safety, raltegravir has become the first-line therapy for treating HIV-infected pregnant women in the developed world [7]. Dolutegravir is now classified as an alternative agent for antiretroviral-naive pregnant women, based on increasing experience, while elvitegravir is not recommended by perinatal guidelines [7]. More knowledge on safety, efficacy and pharmacokinetics in pregnancy may facilitate integrase inhibitors to become first-line therapy in HIV-endemic regions [8], and is therefore of utmost importance.

Pregnancy may alter the pharmacokinetics of antiretroviral drugs [9-12]. The absorption of drugs can be changed because of increased gastric $\mathrm{pH}$ or reduced intestinal motility [13]. Several hemodynamic changes may result in augmented plasma volume and changed tissue perfusion [14], which can influence the volume of distribution and clearance of drugs. Serum protein concentrations may change during pregnancy, which may have consequences for the protein unbound (free) fraction of drugs [15]. Lastly, increased hormone levels during pregnancy may change the expression of metabolizing enzymes, such as UDP-glucuronosyltransferase 1A1 (UGT1A1) [16-18] and cytochrome P450 (CYP) 3A4 [19-22]. Induction of these isoenzymes may lead to increased apparent clearance (CL/ F) and hence a change in exposure to HIV-integrase inhibitors.

In this review, we provide a detailed overview of the pharmacokinetics and potential causes for alterations in the pharmacokinetics of HIV-integrase inhibitors during pregnancy.

\section{Methods}

For each individual HIV-integrase inhibitor, we discuss the impact of pregnancy on the following pharmacological principles: absorption, distribution, protein binding, and metabolism and clearance.

PubMed searches were performed using the following search terms: 'Raltegravir OR Isentress' OR 'Elvitegravir OR Cobicistat OR GS-9137 OR GS-9350 OR Stribild OR Genvoya' OR 'Dolutegravir OR Tivicay OR Triumeq OR GSK1349572' OR 'Cabotegravir OR GSK1265744' OR 'Bictegravir OR GS-9883' in combination with 'Clearance' OR 'Distribution' OR 'Absorption' OR 'Protein binding' OR 'Pharmacokinetics' OR 'Pregnancy' OR 'Bioavailability' OR 'Availability' OR 'Metabolism' OR 'Cytochrome p450 enzyme' OR 'UGT enzyme' OR 'Pglycoprotein transporter' OR 'Breast Cancer Resistance Protein'. Registration information from the European Medicines Agency (EMA) and the US FDA was used, studies reported in ClinicalTrials.gov were screened, and abstracts of relevant international conferences (Conference on Retroviruses and Opportunistic Infections, International Workshop on Clinical Pharmacology of Antiviral Therapy, European AIDS Conference) were also screened.

Renal dysfunction and hepatic impairment are two disease states notorious for decreased plasma protein concentrations [23, 24]; therefore, regulatory agencies advise to assess the unbound pharmacokinetics in plasma in populations with these organ impairments [25-27]. In case data on protein binding were not available in pregnancy, we took clues from other populations with similar decreased serum protein concentrations as pregnant women to estimate the effect of changes in unbound concentration of HIV-integrase inhibitors during pregnancy [28-32]. Results from studies in moderate hepatic [29-31] and severely renally impaired patients [28] can then be useful. However, protein binding may also be decreased due to the accumulation of endogenous compounds, such as bilirubin, in patients with hepatic impairment [33]. In renal impairment, protein binding may be decreased due to displacement by uremic toxins [34]. Therefore, these studies [28-31] are indicative, but not necessarily representative, for changed protein binding in HIV-infected pregnant women. 


\section{Results}

An overview of the available HIV-integrase inhibitors and their doses, routes of administration and current status in pregnancy according to the DHHS guidelines [7] is presented in Table 1 . Table 2 presents the current main pharmacokinetic parameters observed in pregnancy for the different HIV-integrase inhibitors, and Table 3 provides an overview of the hypothetical mechanisms of changed drug metabolism and disposition during pregnancy in relation to the pharmacokinetics of HIV-integrase inhibitors.

\subsection{Raltegravir}

The pharmacokinetics of raltegravir $400 \mathrm{mg}$ twice daily in pregnant women have been described by Blonk et al. [9] ( $n=21$ patients in the third trimester, and $n=18$ patients postpartum) and Watts et al. [10] ( $n=16$ patients in the second trimester, $n=41$ patients in the third trimester, and $n=38$ patients postpartum).

\subsubsection{Absorption}

Raltegravir is a P-glycoprotein (P-gp) substrate, and increased expression of intestinal P-gp during pregnancy could lead to reduced absorption of raltegravir [35, 36], whereas the increased gastric $\mathrm{pH}$ might enhance absorption [37]. Time to reach maximum concentration $\left(T_{\max }\right)$ showed high intersubject variability but was not different from $T_{\max }$ observed in non-pregnant, HIV-infected patients [9, 10]. Therefore, it is probable that pregnancy does not delay the absorption of raltegravir. Maximum concentration $\left(C_{\max }\right)$ values in the second and third trimesters were slightly lower during pregnancy but the variability was large, resulting in overlapping confidence intervals (CIs) when comparing third trimester values with postpartum $C_{\max }$ (see Table 2) $[9,10]$. Similar high variability in $C_{\max }$ has been observed in non-pregnant patients: mean $C_{\max } 2.17 \mathrm{mg} / \mathrm{L}$ [38]. Blonk et al. found a $28 \%$ lower $C_{\max }$ (with $90 \%$ CI of $0.55-1.23$ ) in the third trimester than postpartum [9], whereas Watts et al. found a 26 and $41 \%$ lower $C_{\max }$ in the second and third trimesters, respectively. Pregnancy does not seem to influence the surrogate rate of the absorption parameters $T_{\max }$ and $C_{\max }$.

\subsubsection{Distribution}

In the study by Watts et al. [10], the apparent volume of distribution (V/F) of raltegravir was shown to be increased during the second $(10.6 \%)$ and third trimesters $(37.9 \%)$ compared with postpartum. Furthermore, in the study by Blonk et al. [9], V/F was also increased by $51.7 \%$ in the third trimester versus postpartum. These findings suggest that pregnancy may lead to an increased $\mathrm{V} / \mathrm{F}$ of raltegravir, possibly due to increased volume in pregnancy or decreased bioavailability.

Table 1 Overview of available HIV-integrase inhibitors and their doses, routes of administration and current status in pregnancy, according to DHHS guidelines

\begin{tabular}{|c|c|c|c|}
\hline HIV-integrase inhibitor & Available dose and frequency & $\begin{array}{l}\text { Route of } \\
\text { administration }\end{array}$ & $\begin{array}{l}\text { Status in pregnancy according to } \\
\text { current DHHS guidelines }\end{array}$ \\
\hline Raltegravir (Isentress) & $\begin{array}{l}\text { 1. } 400 \mathrm{mg} \text { bid } \\
\text { 2. } 1200 \mathrm{mg} \text { - two tablets of } 600 \mathrm{mg} \mathrm{qd}\end{array}$ & $\begin{array}{l}\text { 1. Oral } \\
\text { 2. Oral }\end{array}$ & $\begin{array}{l}\text { 1. First-line treatment } \\
\text { 2. Not mentioned in the } \\
\text { guidelines }\end{array}$ \\
\hline $\begin{array}{l}\text { 1. Elvitegravir/cobicistat/emtricitabine/ } \\
\text { tenofovir disoproxil fumarate (Stribild) } \\
\text { 2. Elvitegravir/cobicistat/emtritabine/ } \\
\text { tenofovir/alafenamide (Genvoya) }\end{array}$ & $\begin{array}{l}\text { 1. } 150 / 150 / 200 / 300 \mathrm{mg} \mathrm{qd} \\
\text { 2. } 150 / 150 / 200 / 10 \mathrm{mg} \mathrm{qd}\end{array}$ & $\begin{array}{l}\text { 1. Oral } \\
\text { 2. Oral }\end{array}$ & Not recommended \\
\hline $\begin{array}{l}\text { 1. Dolutegravir (Tivicay) } \\
\text { 2. Dolutegravir/abacavir/lamivudine } \\
\text { (Triumeq) }\end{array}$ & $\begin{array}{l}\text { 1. } 50 \mathrm{mg} \mathrm{qd} \text { or bid (in case of HIV-integrase } \\
\text { resistance or use of co-medication) } \\
\text { 2. } 50 / 600 / 300 \mathrm{mg} \mathrm{qd}\end{array}$ & $\begin{array}{l}\text { 1. Oral } \\
\text { 2. Oral }\end{array}$ & $\begin{array}{l}\text { Alternative treatment (qd and } \\
\text { bid) }\end{array}$ \\
\hline $\begin{array}{l}\text { 1. Cabotegravir induction period }+ \\
\text { abacavir/lamivudine } \\
\text { 2. Cabotegravir long-acting }+ \text { rilpivirine } \\
\text { (RPV) }\end{array}$ & $\begin{array}{l}\text { 1. } 30 \mathrm{mg} \mathrm{qd}+600 / 300 \mathrm{mg} \text { qd (phase III) } \\
\text { 2. } 400 \mathrm{mg} \text { cabotegravir and } 600 \mathrm{mg} \\
\text { rilpivirine on a monthly basis }\end{array}$ & $\begin{array}{l}\text { 1. Oral } \\
\text { 2. IM }\end{array}$ & Not available \\
\hline $\begin{array}{l}\text { Bictegravir/emtricitabine/tenofovir } \\
\text { alafenamide }\end{array}$ & 50/200/25 mg qd (phase III) & Oral & Not available \\
\hline
\end{tabular}

Reference DHHS prenatal guidelines [7]

bid twice daily, qd once daily, DHHS Department of Health and Human Services, IM intramuscular 


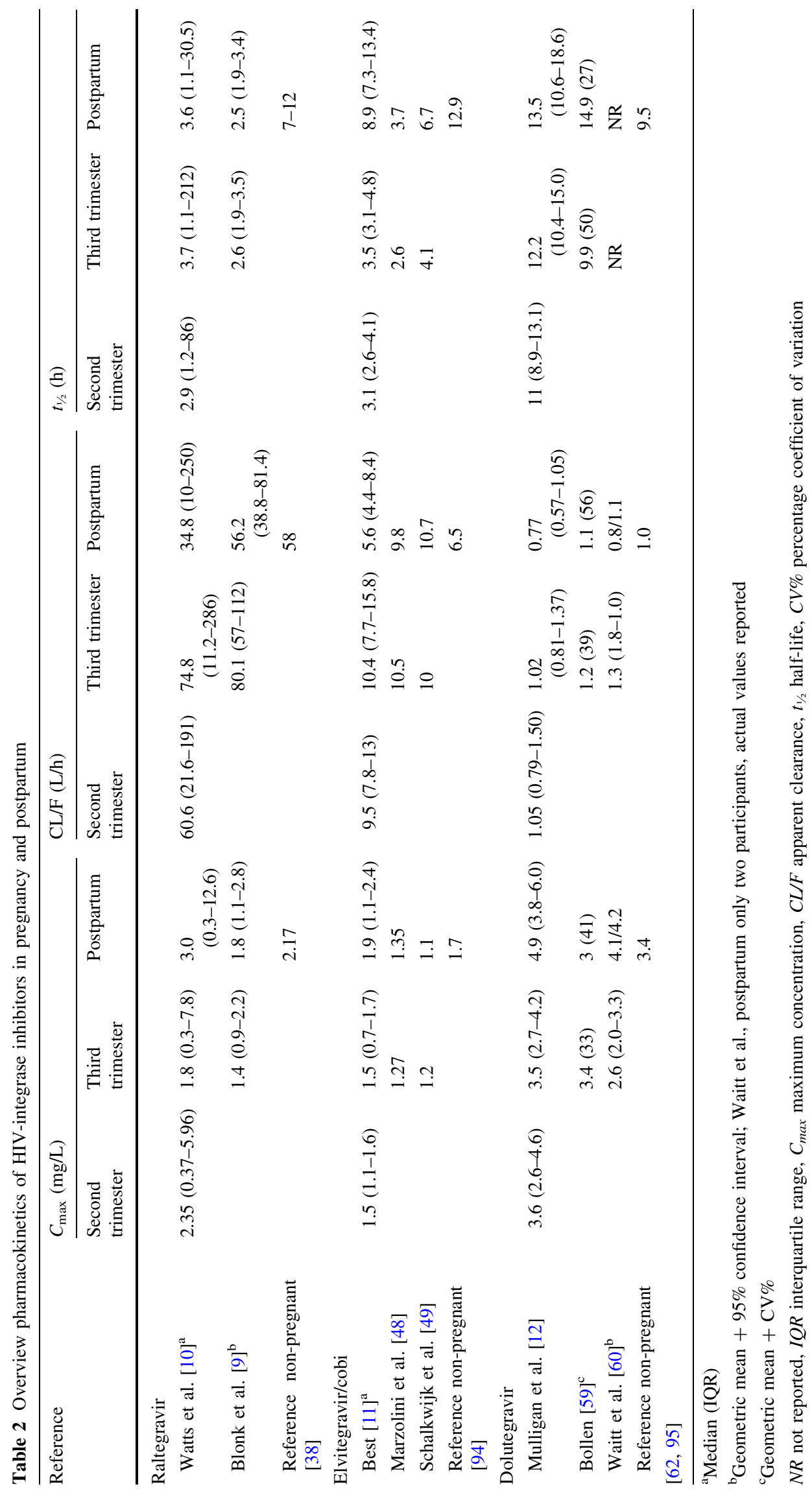


Table 3 Hypothetical mechanisms of changes in drug metabolism and disposition during pregnancy in relation to the pharmacokinetics of HIVintegrase inhibitors

\begin{tabular}{|c|c|c|c|}
\hline \multirow{2}{*}{$\begin{array}{l}\text { Involved metabolic } \\
\text { pathway or drug } \\
\text { transporter } \\
\text { UGT1A1 }\end{array}$} & \multicolumn{2}{|c|}{ Involved HIV-integrase inhibitors } & $\begin{array}{l}\text { Hypothetical mechanisms of changes in drug metabolism and disposition } \\
\text { due to increased hormones during pregnancy, and pharmacokinetic } \\
\text { consequences }\end{array}$ \\
\hline & $\begin{array}{l}\text { Raltegravir } \\
\text { [41, 42] } \\
\text { Dolutegravir } \\
{[64,65]} \\
\text { Cabotegravir } \\
\text { [74] } \\
\text { Bictegravir } \\
\text { [81] } \\
\text { Elvitegravir } \\
\text { [52] }\end{array}$ & $\begin{array}{l}\text { Main metabolizing } \\
\text { route } \\
\text { Main metabolizing } \\
\text { route } \\
\text { Main metabolizing } \\
\text { route } \\
\text { Metabolizing route } \\
\text { equal to CYP3A4 } \\
\text { Minor metabolizing } \\
\text { route }\end{array}$ & $\begin{array}{l}\text { Possible induction of UGT1A1 activity during pregnancy [16-18] could lead } \\
\text { to increased CL/F and decreased exposure to involved HIV-integrase } \\
\text { inhibitors }\end{array}$ \\
\hline CYP3A4 & $\begin{array}{c}\text { Elvitegravir } \\
\text { [52] } \\
\text { Cobicistat } \\
{[53,54]} \\
\text { Dolutegravir } \\
\text { [64, 65] } \\
\text { Bictegravir } \\
\text { [81] }\end{array}$ & $\begin{array}{l}\text { Main metabolizing } \\
\text { route } \\
\text { Main metabolizing } \\
\text { route/inhibitor } \\
\text { Some contribution } \\
\text { to metabolization } \\
\text { Metabolizing route } \\
\text { equal to UGT1A1 }\end{array}$ & $\begin{array}{l}\text { Induction of CYP3A4 activity during pregnancy [19-22] could lead to } \\
\text { increased CL/F and decreased exposure to involved HIV-integrase } \\
\text { inhibitors }\end{array}$ \\
\hline CYP2D6 & $\begin{array}{l}\text { Cobicistat } \\
{[54]}\end{array}$ & $\begin{array}{l}\text { Minor metabolizing } \\
\text { route/inhibitor }\end{array}$ & $\begin{array}{l}\text { Induction of CYP2D6 activity during pregnancy }[55,56] \text { could lead to } \\
\text { increased CL/F and decreased exposure to elvitegravir/cobicistat }\end{array}$ \\
\hline UGT1A9 & $\begin{array}{l}\text { Cabotegravir } \\
\text { [74] }\end{array}$ & $\begin{array}{l}\text { Minor metabolizing } \\
\text { route }\end{array}$ & $\begin{array}{l}\text { Induction of UGT1A9 activity during pregnancy [75] could lead to increased } \\
\text { CL/F and decreased exposure to cabotegravir }\end{array}$ \\
\hline P-gp & $\begin{array}{c}\text { Raltegravir } \\
{[35,36]} \\
\text { Elvitegravir } \\
{[84]} \\
\text { Cobicistat } \\
\text { [87] } \\
\text { Dolutegravir } \\
\text { [65] } \\
\text { Cabotegravir } \\
\text { [86] }\end{array}$ & $\begin{array}{l}\text { Substrate } \\
\text { Substrate/inhibitor/ } \\
\text { inducer } \\
\text { Inhibitor } \\
\text { Substrate } \\
\text { Substrate }\end{array}$ & $\begin{array}{l}\text { Induction of P-gp activity [35], could lead to increased efflux and decreased } \\
\text { exposure to involved HIV-integrase inhibitors } \\
\text { P-gp inhibition by cobicistat [87] may partially reverse increased efflux of } \\
\text { elvitegravir/cobicistat }\end{array}$ \\
\hline BCRP & $\begin{array}{l}\text { Raltegravir } \\
\text { [88] } \\
\text { Cobicistat } \\
\text { [87] } \\
\text { Dolutegravir } \\
\text { [65] } \\
\text { Cabotegravir } \\
\text { [89] }\end{array}$ & $\begin{array}{l}\text { Substrate } \\
\text { Inhibitor } \\
\text { Substrate } \\
\text { Substrate }\end{array}$ & $\begin{array}{l}\text { Induction of BCRP activity [88] could lead to increased efflux and decreased } \\
\text { exposure to involved HIV-integrase inhibitors } \\
\text { BCRP inhibition by cobicistat [87] may partially reverse increased efflux of } \\
\text { cobicistat }\end{array}$ \\
\hline
\end{tabular}

$\overline{U G T \text { UDP-glucuronosyltransferase, } C Y P \text { cytochrome P450, } P \text {-gp P-glycoprotein, BCRP breast cancer resistance protein, } C L / F \text { apparent }}$ clearance

\subsubsection{Protein binding}

Raltegravir shows a moderate protein binding to albumin of approximately 76-83\% [39]. Because no data are available on the unbound fraction of raltegravir in pregnant women, we predicted the unbound fraction of raltegravir during pregnancy based on known protein binding and known decreases in serum albumin concentrations during pregnancy $[14,39]$. The predicted unbound fraction, based on known albumin affinity of raltegravir and a $46 \%$ decrease in serum albumin concentrations during pregnancy [14], is decreased by $<1 \%$ [39], which is in line with the results of a preclinical study in rats where no 
difference in unbound fraction during pregnancy was found [40]. Based on these predictions, we postulate that protein binding of raltegravir is not relevantly impacted by pregnancy and that changes in total plasma concentrations are unlikely to be the result of changed protein binding.

\subsubsection{Metabolism and Clearance}

Raltegravir is primarily metabolized by the UGT1A1 isoenzyme [41, 42]. It has been suggested that UGT1A1 activity is increased during pregnancy, resulting in increased glucuronidation and inactivation of UGT substrates $[16,17]$. This may be attributed to increased progesterone [16] and cortisol [43] levels during pregnancy. Furthermore, raltegravir is a P-gp substrate, in which expression in the liver is increased during pregnancy, which could lead to increased efflux of raltegravir.

The CL/F of raltegravir was significantly increased by $42 \%$ during the third trimester of pregnancy versus postpartum in the study by Blonk et al. [9], and by 74 and $115 \%$ in the second and third trimesters compared with postpartum in the study by Watts et al. [10] (see also Table 2). Lower absorption could also be an underlying mechanism for increased CL/F, however absorption did not seem to be affected in both studies. The increased CL/F, potentially through UGT1A1 induction and/or increased P-gp expression, may have resulted in decreased exposure to raltegravir, varying from $29 \%$ [9] to $50 \%$ [10] in the third trimester compared with postpartum. Although increased $\mathrm{CL} / \mathrm{F}$ of raltegravir is observed during pregnancy, it appears that the half-life $\left(t_{1 / 2}\right)$ of raltegravir is not affected (see Table 2), which is in line with an increased $\mathrm{V} / \mathrm{F}$ $[9,10]$.

\subsubsection{Clinical Relevance}

Lower exposure to raltegravir can be expected during pregnancy as a result of increased CL/F $[9,10]$. There is accumulating evidence that raltegravir exposure correlates with treatment outcome. In the QDMRK study (raltegravir $800 \mathrm{mg}$ once-daily dosing), an association was found between trough concentrations $\left(C_{\text {trough }}\right)$ below a suggested target concentration of $0.020 \mathrm{mg} / \mathrm{L}$ and failure to achieve an undetectable HIV RNA load [44, 45]. Furthermore, Garrido et al. [46] found a trend of lower raltegravir $C_{\text {trough }}$ related to virological failure when raltegravir was administered at $400 \mathrm{mg}$ twice daily. One may argue that due to decreased exposure during pregnancy, patients could be at risk for virological failure. In the study by Blonk et al. [9], $94 \%$ of pregnant women showed a $C_{\text {trough }}$ above the predefined target of $0.02 \mathrm{mg} / \mathrm{L}$. When compared with historical controls, this target attainment is comparable with that observed in non-pregnant, HIV-infected patients receiving a raltegravir-containing regimen (approximately $86.2 \%$ [45]). In addition, Watts et al. [10] found that despite lower exposure to raltegravir during pregnancy, observed trough levels were still comparable with those observed in historical controls. An a priori dose adjustment of raltegravir to counter the effect of pregnancy on pharmacokinetics is therefore not deemed necessary. The pharmacokinetics of the novel $1200 \mathrm{mg}$ once-daily regimen (two new $600 \mathrm{mg}$ tablets) in pregnant women are unknown. Raltegravir $C_{\text {trough }}$ of the $1200 \mathrm{mg}$ once daily regimen were $38 \%$ lower compared with $C_{\text {trough }}$ of the $400 \mathrm{mg}$ twice-daily regimen in healthy volunteers [47]. Consequently, it is relevant to study whether this new once-daily regimen will lead to $C_{\text {trough }}$ above the target of $0.02 \mathrm{mg} / \mathrm{L}$ [45] during pregnancy.

\subsection{Elvitegravir/Cobicistat}

Elvitegravir plasma levels are boosted with cobicistat, a potent CYP3A4 inhibitor; however, the pharmacokinetics of elvitegravir in combination with cobicistat have not yet been extensively evaluated during pregnancy. A conference report of a prospective study $(n=16$ patients in the second trimester, $n=20$ patients in the third trimester, and $n=15$ patients postpartum) by Best [11], as well as case reports of Marzolini et al. [48] and Schalkwijk et al. [49] have described the pharmacokinetics of elvitegravir in HIV-infected pregnant women. In this review, we mainly focus on the study of Best [11].

\subsubsection{Absorption}

Both elvitegravir and cobicistat are P-gp substrates, whereas cobicistat is a P-gp inhibitor; therefore, the effect of increased intestinal P-gp expression on elvitegravir absorption in pregnancy is uncertain. Best found that the elvitegravir $C_{\max }$ was reduced by 32 and $26 \%$, while the cobicistat $C_{\max }$ was reduced by 30 and $36 \%$, in the second and third trimesters, respectively, compared with postpartum [11]. In this study, elvitegravir $C_{\max }$ was below the steady-state mean $C_{\max }(1.7 \mathrm{mg} / \mathrm{L})$ in non-pregnant patients (see Table 2) [50]. Additionally, case reports observed no effect on elvitegravir $C_{\max }$ and reduced cobicistat $C_{\max }[48,49]$ during the third trimester compared with postpartum.

\subsubsection{Distribution}

$\mathrm{V} / \mathrm{F}$ was not reported in the conference report of Best [11] and thefore calculated using derived from the CL/F and $t_{1 / 2}$. V/F of elvitegravir was decreased during the second (40.9\%) and third trimesters (27.0\%) compared with postpartum. Furthermore, the V/F of cobicistat was increased in 
this study during the second $(51.2 \%)$ and third trimesters (42.9\%) compared with postpartum [11].

\subsubsection{Protein Binding}

Elvitegravir shows extensive protein binding to albumin of approximately 98-99\% [30, 51]; cobicistat also highly binds to albumin (97-98\% bound) [30, 51]. Marzolini et al. [48] measured the fraction unbound $\left(f_{\mathrm{u}}\right)$ of elvitegravir and cobicistat in one patient and found that the $f_{\mathrm{u}}$ of elvitegravir was unchanged $\left(f_{\mathrm{u}}=0.3 \%\right)$ when comparing the third trimester with postpartum. Moreover, the $f_{\mathrm{u}}$ of cobicistat was minimally increased during the third trimester, with an $f_{\mathrm{u}}$ of 2.1 versus $1.8 \%$. Besides this case report, clinical studies have not examined the unbound fraction of elvitegravir/cobicistat in pregnant women. A clinical study by Custodio et al. [30] in patients with hepatic impairment found that the free fraction of both elvitegravir (increased from 1.15 to $1.22 \%$ ) and cobicistat (increased from 2.71 to $3.23 \%$ ) was minimally increased compared with healthy subjects, indicating a lack of a relevant effect of hepatic impairment on elvitegravir protein binding [30]. Consequently, limited changes in protein binding of elvitegravir and cobicistat during pregnancy are expected.

\subsubsection{Metabolism and Clearance}

As previously stated, elvitegravir is primarily metabolized by CYP3A4 [52], and its pharmacokinetics are boosted with cobicistat, a strong CYP3A4 inhibitor, to assure adequate exposure. During pregnancy, induction of CYP3A4 is expected, based on in vitro [20] and in vivo data $[21,22]$. This induction may therefore also affect the pharmacokinetics of elvitegravir, and can be explained by two mechanisms. First, since elvitegravir is a substrate of CYP3A4 and the activity of this isoenzyme is induced during pregnancy, increased biotransformation can be expected. Second, induction of CYP3A4 during pregnancy also increases the clearance of cobicistat [53]. As cobicistat is also a CYP2D6 substrate [54], induction of CYP2D6 during pregnancy $[55,56]$ may also lead to increased cobicistat clearance. Variation in cobicistat pharmacokinetics in the clinically relevant range is likely to impact the extent of CYP3A4 inhibition; a study on the pharmacokinetics of elvitegravir and cobicistat in healthy volunteers [57] found that a 33\% dose reduction of cobicistat (from 150 to $100 \mathrm{mg}$ ) resulted in a decreased exposure to cobicistat of approximately $50 \%$. This decreased cobicistat exposure led to decreased elvitegravir exposure of $22 \%$. In pregnant women, decreased cobicistat exposure of 54 and $57 \%$ in the second and third trimesters, respectively, was also observed [11]. Also in pregnant women, a significantly increased clearance of elvitegravir (98 and 73\%) was observed in the second and third trimesters, respectively, compared with postpartum [11] (see Table 2), which resulted in a relevantly decreased exposure to elvitegravir, varying from 49 to $42 \%$ in the second and third trimesters, respectively, compared with postpartum [11]. This decrease in elvitegravir exposure is higher than what was expected as a result of an approximately $50 \%$ reduction in cobicistat exposure, resulting in $22 \%$ lower elvitegravir exposure in healthy volunteers. Therefore, decreased elvitegravir exposure in pregnancy is not only explained by decreased exposure to cobicistat but an additional mechanism may play a role [57]. Lastly, the $t_{1 / 2}$ of elvitegravir ($58 \%$ and $-61 \%)$ and cobicistat $(-26 \%$ and $-36 \%)$ were decreased in pregnant women during the second and third trimesters, respectively, compared with postpartum (see Table 2) [11]. These results imply that both decreased exposure to cobicistat and increased metabolism of elvitegravir by CYP3A4 may explain the observed highly decreased exposure to elvitegravir during pregnancy.

\subsubsection{Clinical Relevance}

In general, decreased exposure to elvitegravir/cobicistat can be expected in pregnant women as a result of reduced boosting by cobicistat and/or increased clearance of elvitegravir [11]. It is known that elvitegravir exposure is related to antiviral activity in treatment-naive and -experienced patients [58]. DeJesus et al. [58] found that an elvitegravir target concentration of $0.13 \mathrm{mg} / \mathrm{L}$ was needed to produce a $90 \%$ effective response $\left(\mathrm{EC}_{90}\right)$, measured as HIV-RNA viral load after 10 days of treatment with elvitegravir. In clinical studies on pregnancy, exposure to elvitegravir appeared to be below this target concentration of $0.13 \mathrm{mg} / \mathrm{L}$. Best [11] found a median elvitegravir $C_{\text {trough }}$ of $0.0249 \mathrm{mg} / \mathrm{L}$ (interquartile range [IQR] $0.0173-0.0807$ ) and $0.0570 \mathrm{mg} / \mathrm{L}$ (IQR 0.0147-0.0940) during the second and third trimesters of pregnancy, respectively. Additionally, the case reports of Marzolini et al. [48] and Schalkwijk et al. [49] found a total elvitegravir $C_{\text {trough }}$ below the target of elvitegravir ( 0.018 and $0.06 \mathrm{mg} / \mathrm{L}$, respectively). The results of these studies imply inadequate exposure to elvitegravir during pregnancy and hence an increased risk of virological failure. As a result of this, elvitegravir/cobicistat is not recommended in HIV-infected pregnant women according to perinatal guidelines [7].

\subsection{Dolutegravir}

The pharmacokinetics of dolutegravir have not been thoroughly evaluated during pregnancy. A prospective study by Mulligan et al. [12] ( $n=15$ patients in the second trimester, $n=28$ patients in the third trimester, and $n=22$ patients postpartum), as well as two conference reports of 
prospective studies by Bollen [59] ( $n=8$ patients in the third trimester, $n=5$ patients postpartum) and Waitt et al. [60] $(n=7$ patients in the third trimester and $n=2$ postpartum) have described the pharmacokinetics of dolutegravir in HIV-infected pregnant women. The report by Bollen includes the data from a case reported by Schalkwijk et al. [61].

\subsubsection{Absorption}

As with most HIV-integrase inhibitors, dolutegravir is a P-gp substrate and therefore absorption may be decreased due to increased intestinal P-gp expression during pregnancy. There was no difference in $T_{\max }$ during pregnancy compared with postpartum $[12,59]$, and $C_{\max }$ was not substantially different during pregnancy compared with postpartum, but was marginally lower. Mulligan et al. found 25 and $27 \%$ lower $C_{\max }$ in the second and third trimesters, respectively [12]. Additionally, Bollen observed a minimally increased $C_{\max }(5 \%)$ in the third trimester compared with postpartum [59], while Waitt et al. [60] noted a $36 \%$ lower $C_{\max }$ in the third trimester compared with postpartum. Overall, the $C_{\max }$ observed in the studies in pregnancy did not deviate from the $C_{\max }$ observed in non-pregnant patients, i.e. $3.4 \mathrm{mg} / \mathrm{L}$, with a variance of $27 \%$ [62]. We therefore suggest that pregnancy does not influence absorption of dolutegravir.

\subsubsection{Distribution}

$\mathrm{V} / \mathrm{F}$ was derived from the calculated $\mathrm{CL} / \mathrm{F}$ and $t_{1 / 2}$ in the paper by Mulligan et al. [12], and from the AUC, dose and $t_{1 / 2}$ in the conference report of Bollen [59]. Furthermore, in the study by Mulligan et al. [12], V/F was shown to be increased during the second $(11 \%)$ and third trimesters (20\%) compared with postpartum. In contrast, Bollen [59] found that $\mathrm{V} / \mathrm{F}$ was decreased by $27.5 \%$ during the third trimester compared with postpartum. The mechanism behind this altered $\mathrm{V} / \mathrm{F}$ of dolutegravir in pregnancy is still unclear.

\subsubsection{Protein Binding}

Dolutegravir is approximately $99 \%$ bound to plasma proteins, mainly to albumin $[29,63]$. Until now, no studies have analyzed the unbound fraction of dolutegravir in pregnant women. To predict an effect, we have extrapolated knowledge from studies in moderate hepatically impaired patients. A clinical study by Song et al. [29] found that lower albumin concentrations in patients with hepatic impairment led to an increased $f_{\mathrm{u}}$ of dolutegravir, from 0.23 to $0.54 \%$. A similar change in the $f_{\mathrm{u}}$ of dolutegravir may also occur during pregnancy.

\subsubsection{Metabolism and Clearance}

Dolutegravir is primarily metabolized by UGT1A1 enzymes, and secondarily by CYP3A4, oxidative defluorination and glutathione substitution [64, 65]. As stated previously, induction of both UGT1A1 activity [16, 17] and CYP3A4 activity [19-22] may occur during pregnancy. While the induction of UGT1A1 activity may be attributed to increased progesterone [16] and cortisol [43] levels during pregnancy, many other hormones may induce expression of CYP3A4 [20, 66, 67]. Furthermore, increased expression of hepatic P-gp might increase the efflux, and hence increase the clearance of dolutegravir. Induction of these pathways may increase CL/F and contribute to a decreased exposure to dolutegravir during pregnancy.

Increased $\mathrm{CL} / \mathrm{F}$ is in line with the results from the study by Mulligan et al. [12], where the CL/F of dolutegravir was significantly increased by $40 \%$ during the third trimester of pregnancy versus postpartum. In this study, decreased exposure to dolutegravir was observed, varying from $37 \%$ in the second trimester to $29 \%$ in the third trimester compared with postpartum[12]. Waitt et al. also observed a modest reduction in exposure in the third trimester [60]. However, Bollen [59] did not observe a difference in either the derived $\mathrm{CL} / \mathrm{F}$ or in exposure during the third trimester compared with postpartum. Dolutegravir exposure during pregnancy was similar $(47.6$ and $49.2 \mathrm{mg} \mathrm{h} / \mathrm{L}$ reported by Mulligan et al. [12], $39.4 \mathrm{mg} \mathrm{h} / \mathrm{L}$ reported by Waitt et al. [60], and $42.9 \mathrm{mg} \mathrm{h} / \mathrm{L}$ reported by Bollen [59], which are also similar to exposure of non-pregnant adults, i.e. 53.8 and $53.6 \mathrm{mg} \mathrm{h} / \mathrm{L}$ in two clinical trials [68]). The postpartum exposure reported by Mulligan et al. was high compared with the postpartum exposure reported by Bollen, i.e. 65 versus $44.8 \mathrm{mg} \mathrm{h} / \mathrm{L}[12,59]$. This difference seems to drive the discrepancy between the presence or absence of a pregnancy effect. Finally, Mulligan et al. [12] and Bollen [59] found a decreased $t_{1 / 2}$ during pregnancy compared with postpartum (see Table 2).

\subsubsection{Clinical Relevance}

Conflicting results have been reported regarding exposure to dolutegravir during pregnancy. Either a decreased, yet not clinically relevant, or an unchanged exposure to dolutegravir was observed during pregnancy $[12,59,60]$. The preliminary results of the pharmacokinetic studies in pregnant women are promising as, in the studies by Bollen and Waitt et al., dolutegravir $C_{\text {trough }}$ in all pregnant women were above this minimum effective concentration of 0.064 $\mathrm{mg} / \mathrm{L}$ for treatment-naive patients $[69,70]$, both during and after pregnancy. Mulligan et al. reported that the $C_{\text {trough }}$ during pregnancy was 11- to 14-fold greater than the EC90 
of $0.064 \mathrm{mg} / \mathrm{L}$. Despite lower total $C_{\text {trough }}$ levels during pregnancy $[12,59]$, it is probable that pregnancy does not lead to clinically relevant changes in both exposure and treatment outcome of dolutegravir. We therefore propose that it is not necessary to adjust the dose of dolutegravir during pregnancy in treatment-naive patients. However, a higher exposure may be necessary in patients with a documented or clinically suspected resistance against dolutegravir or in patients with drug interactions; this can be reached by doubling the dose of dolutegravir [71]. We do not know whether adequate exposure is reached in pregnant patients in whom doubling the dose of dolutegravir is necessary due to inadequate exposure to, or resistance with, the single-dose regimen.

\subsection{Cabotegravir and Bictegravir}

The pharmacokinetics of cabotegravir have not yet been evaluated during pregnancy. Injectable cabotegravir is a long-acting HIV-integrase-inhibiting agent in development and has the advantage of requiring once monthly or longer dosing intervals. In an ongoing phase III trial, HIV-infected naive patients are receiving dolutegravir, abacavir and lamivudine as induction therapy, followed by cabotegravir and rilpivirine as oral lead-in, and, finally, intramuscular injections of long-acting cabotegravir and rilpivirine as maintenance therapy [72].

The pharmacokinetics of bictegravir have not been examined during pregnancy. Bictegravir is being investigated in phase III clinical trials in co-formulation with emtricitabine and tenofovir alafenamide. In this review, we hypothesize the potential effects of pregnancy on the pharmacokinetics of cabotegravir and bictegravir.

\subsubsection{Cabotegravir}

As cabotegravir is a P-gp substrate, absorption of the oral formulation might be influenced by pregnancy; however, for the injectable formulation, this is not applicable. Cabotegravir shows high protein binding of $>99 \%$ and is mainly bound to albumin [73]. Parasrampuria et al. [28] studied the pharmacokinetics of cabotegravir in patients with severe renal impairment, a patient group in which hypoalbuminemia can also occur, and found that the $f_{\mathrm{u}}$ of cabotegravir was minimally increased from 0.14 to $0.18 \%$, and from 0.11 to $0.17 \%$, in patients with severe renal impairment compared with healthy subjects, at 2 and $24 \mathrm{~h}$ post-dose, respectively. Consequently, we do not expect clinically relevant changes in the protein binding of cabotegravir during pregnancy. Cabotegravir is mainly metabolized through glucuronidation by UGT1A1 and UGT1A9 [74]. The activity of UGT1A1 [16, 17] and UGT1A9 [75] may be increased during pregnancy, mainly due to increased levels of progesterone [16], cortisol [43] and estradiol [75]. It is known that the clearance of paracetamol [76-78], also a UGT1A1 and UGT1A9 substrate, was increased in pregnant women compared with non-pregnant controls, varying from $36 \%$ [77] to 58\% [76]. Hepatic clearance might also be increased due to increased expression of hepatic P-gp transporters during pregnancy. These processes are likely to affect the pharmacokinetics of cabotegravir and result in reduced exposure.

\subsubsection{Clinical Relevance}

The place of parenteral cabotegravir in pregnancy is unknown. One may argue whether this long-acting injectable agent is appropriate for treating HIV-infected pregnant women as its long apparent $t_{1 / 2}$ can be problematic if pregnant women need to switch to other combination antiretroviral therapy (cART); for example, in case of adverse events. Moreover, it is unknown whether maternal and fetal safety of cabotegravir can be assured during pregnancy. We hypothesized whether pregnancy may lead to clinically relevant reduced exposure to cabotegravir. In general, decreased exposure to cabotegravir can be expected during pregnancy, caused by potential increased clearance. It is known that cabotegravir exposure is related to antiviral activity. Margolis et al. [79] found that the median cabotegravir $C_{\text {trough }}$ was 16 (for $400 \mathrm{mg}$ of cabotegravir administered intramuscularly once monthly) to 27 times (for $30 \mathrm{mg}$ of cabotegravir administered orally) above the defined in vitro protein-adjusted $90 \%$ inhibitory concentration of $0.166 \mathrm{mg} / \mathrm{L}$ against wild-type HIV in nonpregnant HIV-infected patients. This indicates that these concentrations were adequate for reaching viral suppression. It is plausible that a decrease of cabotegravir $C_{\text {trough }}$ during pregnancy would be similar to paracetamol, i.e. an approximately two-fold decrease [76-78], where the margin in a non-pregnant women is a factor of 16 above the target. A dose adjustment of cabotegravir for pregnant women might therefore not be necessary but requires prospective evaluation.

\subsubsection{Bictegravir}

No information is available on whether bictegravir is a P-gp substrate, and it is unclear whether pregnancy may alter the absorption of bictegravir. It is also unclear whether pregnancy will lead to changes in the V/F of bictegravir. Bictegravir shows very high protein binding of approximately $99.7 \%$ [80]. To hypothesize whether the predicted $f_{\mathrm{u}}$ of bictegravir changes during pregnancy, we extrapolated data from patients with moderate hepatic impairment to pregnant women. A study from Zhang [31] found that the $f_{\mathrm{u}}$ of bictegravir was increased in patients 
with moderate hepatic impairment $\left(f_{\mathrm{u}}=0.81 \%\right)$ compared with healthy subjects $\left(f_{\mathrm{u}}=0.61 \%\right)$. In line with these findings, one might expect a similar change in the $f_{\mathrm{u}}$ of bictegravir during pregnancy, indicating the lack of a relevant effect of pregnancy on bictegravir protein binding. Bictegravir is mainly metabolized by CYP3A4 and UGT1A1 in an equal proportion [81]. Both CYP3A4 [19-22] and UGT1A1 activity [16, 17] may be increased during pregnancy. Both of these processes may therefore lead to increased $\mathrm{CL} / \mathrm{F}$, and hence decreased exposure to bictegravir during pregnancy.

\subsubsection{Clinical Relevance}

It is known that bictegravir exposure is related to antiviral activity. Gallant [82] found that mean bictegravir $C_{\text {trough }}$ was 13 -fold greater than the defined in vitro protein-adjusted $95 \%$ inhibitory concentration of $162 \mathrm{ng} / \mathrm{mL}$ against wild-type HIV for bictegravir $50 \mathrm{mg}$ in non-pregnant HIVinfected patients. We do not expect that pregnancy will reduce $C_{\text {trough }} 13$-fold; pregnancy effects are generally in the magnitude of a factor two. The most prominent effect that was observed in pregnancy was a 7.5-fold reduction of elvitegravir $C_{\text {trough, }}$ also a CYP3A4 and UGT1A1 substrate, but elvitegravir exposure is also dependent on boosting by cobicistat, which is likewise reduced during pregnancy. Therefore, we expect that bictegravir $C_{\text {trough }}$ $>162 \mathrm{ng} / \mathrm{mL}$ will likely be reached during pregnancy [11], however this needs to be assessed prospectively. Furthermore, new studies need to prospectively evaluate the unbound concentrations of bictegravir during pregnancy to prove that pregnancy does not relevantly affect bictegravir protein binding.

\section{Discussion and Knowledge Gaps}

For absorption, we reported the $C_{\max }$ and $T_{\max }$ as surrogate parameters for the rate of absorption. However, these parameters are not only affected by absorption rate, volume of distribution and bioavailability but also by the CL/F of a drug. One should be aware that a potential change in $C_{\max }$ and $T_{\max }$ during pregnancy does not directly imply changes in absorption.

For volume of distribution, we reported the $\mathrm{Vd} / \mathrm{F}$ derived from non-compartmental analysis of pharmacokinetic curves at steady-state (after oral dosing). The reader should be aware that this parameter also depends on bioavailability, and changes in $\mathrm{Vd} / \mathrm{F}$ may not reflect a change in volume.

\subsection{Knowledge Gaps}

The ultimate goal of antiretroviral therapy in pregnant women is the prevention of mother-to-child transmission (MTCT) of HIV and optimal maternal treatment, for which adequate exposure is necessary. Unfortunately, the clinical pharmacokinetics of antiretroviral drugs are generally not studied in pregnant women during clinical drug development. However, after approval, these drugs are also prescribed for pregnant women to prevent MTCT of HIV and to protect the health of the mother. To better understand the clinical pharmacokinetics in pregnant women, and quantitatively predict the magnitude of changes in exposure for new drugs, it is important to accurately chart the mechanisms underlying these changes. More knowledge on this may further facilitate and guide the development of effective and safe treatment of HIV-infected pregnant women.

In this review, we discuss that pregnancy leads, or may lead, to a reduction in pharmacokinetic exposure to HIVintegrase inhibitors, which may endanger viral suppression.

Of all HIV-integrase inhibitors, the most experience has been obtained with raltegravir $400 \mathrm{mg}$ twice daily during pregnancy, and this is now marked as first-line therapy [7]. Besides raltegravir $400 \mathrm{mg}$ twice daily and elvitegravir/cobicistat and dolutegravir $50 \mathrm{mg}$ once daily, there is limited clinical experience regarding the use of other HIV-integrase inhibitors during pregnancy. For the new HIV-integrase inhibitors bictegravir and cabotegravir, it is very difficult to conclude whether pregnancy leads to a clinically relevant reduction in exposure, and whether the safety of the unborn child is assured. Knowledge on the pharmacokinetics of these drugs in pregnancy is very relevant and can be used to inform perinatal guidelines. To illustrate this, elvitegravir/cobicistat is not recommended for pregnant women [7] because of inadequate exposure during pregnancy $[11,48,49]$. We do not know whether adequate exposure to, and viral suppression of, raltegravir $1200 \mathrm{mg}$ once daily, dolutegravir $50 \mathrm{mg}$ twice daily, and bictegravir and cabotegravir can be reached using standard dosing regimens in pregnant women. In particular, for new antiretrovirals (cabotegravir and bictegravir) it is important to determine maternal safety and efficacy during pregnancy. One also needs to determine whether these new antiretrovirals do not lead to congenital abnormalities and teratogenicity. Because therapy with long-acting injectables cannot simply be stopped during pregnancy, this issue is of utmost importance for cabotegravir.

Besides the latter, the knowledge gaps on the mechanisms behind the changes in the pharmacokinetics of HIVintegrase inhibitors during pregnancy need to be studied to optimize antiretroviral treatment during pregnancy. 
Increased progesterone levels during pregnancy may induce UGT1A1-mediated metabolism [16, 83]; UGT1A1 plays a role in the metabolism of all HIV-integrase inhibitors. Induced UGT1A1 expression leading to increased intrinsic clearance may explain the observed decreased exposure to, for example, raltegravir during pregnancy. However, we do not know to what degree UGT1A1 induction explains variability in the pharmacokinetics of HIV-integrase inhibitors. Analyzing metabolites in pregnancy might help to elucidate this knowledge gap.

Furthermore, we do not know whether pregnancy-related CYP3A4 induction plays a major role in increased clearance and decreased exposure to HIV-integrase inhibitors. Since elvitegravir, bictegravir and dolutegravir are all partly converted by CYP3A4, this may be an important factor in altered exposure of these drugs in pregnancy. Determination of metabolites could help to understand the role of altered CYP3A4 metabolism in pregnancy.

The extent to which altered drug transporter activity in pregnancy influences the pharmacokinetics of HIV-integrase inhibitors in pregnancy is currently unclear. Potential effects of changes in transporter expression are presented in Table 3. Since raltegravir [35, 36], elvitegravir/cobicistat [84], dolutegravir [85] and cabotegravir [86] are all substrates of P-gp (for bictegravir this information was not available), one may expect that increased expression of P-gp during pregnancy may lead to decreased absorption and increased hepatic efflux. Elvitegravir disposition may be subject to a more complex mechanism because of coadministration of cobicistat. Increased elvitegravir efflux during pregnancy may potentially be partially reversed by cobicistat, which inhibits P-gp activity [87]. However, should relevant P-gp inhibition occur, this did not affect $\mathrm{CL} / \mathrm{F}$ as we saw a marked increase in this parameter of elvitegravir during pregnancy [11]. Additionally, since raltegravir [88], cobicistat [87], dolutegravir [65] and cabotegravir [89] are all substrates of breast cancer resistance protein (BCRP), it can be expected that increased expression of BCRP in pregnant women may also lead to increased efflux. Generally, increased efflux may result in decreased exposure to HIV-integrase inhibitors during pregnancy, and hence an increased risk of viral MTCT. However, changes in drug transporter activity and expression during pregnancy, and their impact on exposure to HIV-integrase inhibitors, have not yet been examined in HIV-infected pregnant women and therefore remains a knowledge gap.

The relationship between altered hormone levels in pregnancy and induction/inhibition of enzymes and transporters, as well as other physiological changes taking place during pregnancy, has not been studied for HIV-integrase inhibitors. Population pharmacokinetic analysis could help to find relevant covariates (such as hormonal concentrations during pregnancy) influencing the pharmacokinetics of these drugs in pregnancy.

A knowledge gap exists on how enterohepatic circulation of HIV-integrase inhibitors changes during pregnancy. There is evidence that raltegravir [90] and dolutegravir [64] undergo enterohepatic circulation. One may expect that a possibly higher degree of enterohepatic circulation during pregnancy, caused by increased UGT1A1 activity, increased glucuronidation, subsequent active biliary excretion of the deconjugated glucuronide, and reabsorption, may change the pharmacokinetics of HIV-integrase inhibitors. This mechanism has not been studied in detail in pregnancy.

Furthermore, very little information is available on the unbound concentrations of HIV-integrase inhibitors during pregnancy. This may provide difficulty in assessing the relation between exposure and response during pregnancy (virologic response or toxicity), as, in most cases, only the unbound drug is pharmacologically active. Generally, changes in protein binding are not clinically relevant as the unbound concentration remains unchanged [91]. It should be noted that if only total plasma concentrations are assessed, decreased plasma protein binding may be incorrectly interpreted as increased clearance due to the decreased total concentration, despite unchanged unbound concentrations. Consequently, it is key to measure the unbound concentrations of HIV-integrase inhibitors during pregnancy [92]. More information on this will help us to evaluate the clinical relevance of a potential decrease in total exposure during pregnancy.

Lastly, another important knowledge gap exists on the safety of the unborn child during therapy with HIV-integrase inhibitors in pregnant women. Information should be collected to indicate for which new HIV-integrase inhibitors adequate safety of the unborn child can be assured during pregnancy. For example, by collecting safety information of HIV-infected pregnant women in an international registry, such as the Antiretroviral Pregnancy Registry (APRegistry) [93], one will gain more insight into the safety of both the mother and the unborn child during pregnancy.

\section{Conclusions}

Pregnancy decreases exposure to raltegravir and elvitegravir. Exposure to dolutegravir may also be decreased in pregnancy, although conflicting results on this issue have been reported in the literature. Despite potential decreased exposure, $C_{\text {trough }}$ above the target concentration is reached with raltegravir $400 \mathrm{mg}$ twice daily and dolutegravir $50 \mathrm{mg}$ once daily during pregnancy. Elvitegravir $C_{\text {trough }}$ is below the target concentration in most women during pregnancy, 
indicating possible inadequate exposure. It is unknown whether adequate exposure of cabotegravir, bictegravir, raltegravir $1200 \mathrm{mg}$ once daily, and dolutegravir $50 \mathrm{mg}$ twice daily is reached during pregnancy, but decreased exposure is expected; further studies are required to prospectively assess the clinical relevance and extent of decreased exposure. Until such time as these new studies have been performed, it is recommended that these new HIVintegrase inhibitors not be used during pregnancy. If pregnant women are already using the new HIV-integrase inhibitors, we recommend performing therapeutic drug monitoring of these agents, if available, and monitoring viral load in HIV-infected pregnant women using this class of drugs. For raltegravir, elvitegravir and dolutegravir, target concentrations can be defined and have been reported in this paper under the clinical relevance section of each drug. Furthermore, knowledge gaps on the mechanisms behind the changes in the pharmacokinetics of HIV-integrase inhibitors during pregnancy still exist. Further studies are required to unravel the mechanisms behind the changes in the pharmacokinetics of HIV-integrase inhibitors during pregnancy. More information on these mechanisms will also help us to predict changes in the pharmacokinetics and safety of new HIV-integrase inhibitors during pregnancy. More knowledge on changes in the pharmacokinetics of these drugs can be used for recommendations in perinatal guidelines, which helps us to optimize pharmacotherapy with HIV-integrase inhibitors in pregnant women.

\section{Compliance with Ethical Standards}

Funding No sources of funding were used to assist in the preparation of this review.

Conflict of interest Angela Colbers and David Burger run the PANNA network, which is supported by the European AIDS Treatment Network, The European Commission, DG Research, Sixth Framework Program, contract LSHP-CT-2006-037570, Bristol-Myers Squibb, Merck Sharp \& Dohme Corp, Gilead Sciences, ViiV Healthcare and Janssen Pharmaceuticals NV. Ruben van der Galiën, Rob ter Heine, Rick Greupink, Stein J. Schalkwijk, and Antonius E. van Herwaarden have no conflicts of interest to declare.

Open Access This article is distributed under the terms of the Creative Commons Attribution-NonCommercial 4.0 International License (http://creativecommons.org/licenses/by-nc/4.0/), which permits any noncommercial use, distribution, and reproduction in any medium, provided you give appropriate credit to the original author(s) and the source, provide a link to the Creative Commons license, and indicate if changes were made.

\section{References}

1. Messiaen P, Wensing AM, Fun A, Nijhuis M, Brusselaers N, Vandekerckhove L. Clinical use of HIV integrase inhibitors: a systematic review and meta-analysis. PLoS One. 2013;8:e52562.
2. Department of Health and Human Services. Guidelines for the use of antiretroviral agents in HIV-1-infected adults and adolescents. 2017. https://aidsinfo.nih.gov/guidelines/html/1/adult-andadolescent-arv-guidelines/10/initiation-of-antiretroviral-therapy. Accessed 3 Feb 2018.

3. Sighem Avea. HIV monitoring report 2016. HIV infection in the Netherlands. First edition: November 2016. https://www.hivmonitoring.nl/files/6614/7999/7485/HIV_Monitoring_Report_ 2016_24_Nov.pdf. Accessed 29 Nov 2017.

4. Venturelli SMW, Carder M, Ramzan F, Negedu O, Bailey AC, Mackie NE, Fidler S. START: how long does it take to start antiretroviral therapy (ART)? Poster abstract P18. HIV medicine. 2017;18 Suppl S1: 14-70. http://onlinelibrary.wiley.com/doi/10. 1111/hiv.12513/epdf. Accessed 10 Jan 2018.

5. Thomson-Glover RMK, Chaopnda M. ARTs in naive patients: are we following national or local prescribing guidelines? Poster Abstract P2. HIV Medicine. 2017;18 Suppl S1:14-70. http:// onlinelibrary.wiley.com/doi/10.1111/hiv.12513/epdf. Accessed 10 Jan 2018.

6. Kingston MSA, McBrien B, Ariel J, Price A. Before and after the algorithm. Poster Abstract P3. HIV Medicine 2017;18 Suppl S1: 14-70. http://onlinelibrary.wiley.com/doi/10.1111/hiv.12513/ epdf. Accessed 10 Jan 2018.

7. Department of Health and Human Services. Recommendations for use of antiretroviral drugs in pregnant HIV-1-infected women for maternal health and interventions to reduce perinatal hiv transmission in the United States. https://aidsinfo.nih.gov/ contentfiles/lvguidelines/perinatalgl.pdf. Accessed 20 Nov 2017.

8. Phillips AN, Cambiano V, Nakagawa F, Revill P, Jordan MR, Hallett TB, et al. Cost-effectiveness of public-health policy options in the presence of pretreatment NNRTI drug resistance in sub-Saharan Africa: a modelling study. Lancet HIV. 2018;5(3):e146-54.

9. Blonk MI, Colbers AP, Hidalgo-Tenorio C, Kabeya K, Weizsacker K, Haberl AE, et al. Raltegravir in HIV-1-infected pregnant women: pharmacokinetics, safety, and efficacy. Clin Infect Dis. 2015;61:809-16.

10. Watts DH, Stek A, Best BM, Wang J, Capparelli EV, Cressey $\mathrm{TR}$, et al. Raltegravir pharmacokinetics during pregnancy. J Acquir Immune Defic Syndr. 2014;67:375-81.

11. Best BM. Elvitegravir/cobicistat pharmacokinetics in pregnancy and postpartum (2017). Poster presented at the conference on retroviruses and opportunistic infections (CROI); 13-16 Feb 2017: Seattle, WA [poster number 755]. http://impaactnetwork. org/DocFiles/CROI2017/P1026s_Best_CROI2017_poster.pdf. Accessed 7 Aug 2017.

12. Mulligan N, Best BM, Wang J, Capparelli EV, Stek A, Barr E, et al. Dolutegravir pharmacokinetics in pregnant and postpartum women living with HIV. AIDS. 2018;32(6):729-37.

13. Dawes M, Chowienczyk PJ. Pharmacokinetics in pregnancy. Best Pract Res Clin Obstet Gynaecol. 2001;15:819-26.

14. Abduljalil K, Furness P, Johnson TN, Rostami-Hodjegan A, Soltani H. Anatomical, physiological and metabolic changes with gestational age during normal pregnancy: a database for parameters required in physiologically based pharmacokinetic modelling. Clin Pharmacokinet. 2012;51:365-96.

15. Perucca E, Ruprah M, Richens A. Altered drug binding to serum proteins in pregnant women: therapeutic relevance. J R Soc Med. 1981;74:422-6.

16. Jeong H, Choi S, Song JW, Chen H, Fischer JH. Regulation of UDP-glucuronosyltransferase (UGT) $1 \mathrm{~A} 1$ by progesterone and its impact on labetalol elimination. Xenobiotica. 2008;38:62-75.

17. Hirashima R, Michimae H, Takemoto H, Sasaki A, Kobayashi Y, Itoh $\mathrm{T}$, et al. Induction of the UDP-glucuronosyltransferase 1A1 during the perinatal period can cause neurodevelopmental toxicity. Mol Pharmacol. 2016;90:265-74. 
18. Fischer JH, Sarto GE, Hardman J, Endres L, Jenkins TM, Kilpatrick SJ, et al. Influence of gestational age and body weight on the pharmacokinetics of labetalol in pregnancy. Clin Pharmacokinet. 2014;53:373-83.

19. Zhang H, Wu X, Wang H, Mikheev AM, Mao Q, Unadkat JD. Effect of pregnancy on cytochrome P450 3a and P-glycoprotein expression and activity in the mouse: mechanisms, tissue specificity, and time course. Mol Pharmacol. 2008;74:714-23.

20. Papageorgiou I, Grepper S, Unadkat JD. Induction of hepatic CYP3A enzymes by pregnancy-related hormones: studies in human hepatocytes and hepatic cell lines. Drug Metab Dispos. 2013;41:281-90.

21. van Heeswijk RP, Khaliq Y, Gallicano KD, Bourbeau M, Seguin I, Phillips EJ, et al. The pharmacokinetics of nelfinavir and M8 during pregnancy and post partum. Clin Pharmacol Ther. 2004;76:588-97.

22. Aweeka FT, Hu C, Huang L, Best BM, Stek A, Lizak P, et al. Alteration in cytochrome P450 3A4 activity as measured by a urine cortisol assay in HIV-1-infected pregnant women and relationship to antiretroviral pharmacokinetics. HIV Med. 2015;16:176-83.

23. Blaschke TF. Protein binding and kinetics of drugs in liver diseases. Clin Pharmacokinet. 1977;2:32-44.

24. Reidenberg MM, Drayer DE. Alteration of drug-protein binding in renal disease. Clin Pharmacokinet. 1984;9(Suppl 1):18-26.

25. US FDA. Pharmacokinetics in patients with impaired renal function - study design, data analysis, and impact on dosing and labeling. $1998 . \quad$ https://www.fda.gov/downloads/Drugs/ GuidanceComplianceRegulatoryInformation/Guidances/ ucm072127.pdf. Accessed Apr 2018.

26. US FDA. Guidance for industry; pharmacokinetics in patients with impaired hepatic function: study design, data analysis, and impact on dosing and labeling. 2003. http://www.fda.gov/ downloads/Drugs/GuidanceComplianceRegulatoryInformation/ Guidances/UCM072123.pdf. Accessed 21 Jan 2018.

27. US FDA. Pharmacokinetics in pregnancy—study design, data analysis, and impact on dosing and labeling. 2004. https://www. fda.gov/downloads/Drugs/.../Guidances/ucm072133.pdf. Accessed 2 Mar 2018.

28. Parasrampuria R, Ford S, Lou Y, Fu C, Bakshi K, Tenorio A, et al. Pharmacokinetics of cabotegravir in subjects with severe renal impairment. Open Forum Infectious Diseases. 2017 Fall; 4 Suppl 1: S429-S430.

29. Song IH, Borland J, Savina PM, Chen S, Patel P, Wajima T, et al. Pharmacokinetics of single-dose dolutegravir in HIV-seronegative subjects with moderate hepatic impairment compared to healthy matched controls. Clin Pharmacol Drug Dev. 2013;2:342-8.

30. Custodio JM, Rhee M, Shen G, Ling KH, Kearney BP, Ramanathan S. Pharmacokinetics and safety of boosted elvitegravir in subjects with hepatic impairment. Antimicrob Agents Chemother. 2014;58:2564-9.

31. Zhang H. The effect of hepatic or renal impairment on bictegravir pharmacokinetics. In: Presented on the 18th international workshop on clinical pharmacology of antiviral therapy; June 14-17, 2017, Chicago, IL. http://www.natap.org/2017/Pharm/Pharm_31. htm. Accessed 10 Jan 2018.

32. Bernardi M, Ricci CS, Zaccherini G. Role of human albumin in the management of complications of liver cirrhosis. J Clin Exp Hepatol. 2014;4:302-11.

33. Palatini P, Orlando R, De Martin S. The effect of liver disease on inhibitory and plasma protein-binding displacement interactions: an update. Expert Opin Drug Metab Toxicol. 2010;6:1215-30.

34. Keller F, Maiga M, Neumayer HH, Lode H, Distler A. Pharmacokinetic effects of altered plasma protein binding of drugs in renal disease. Eur J Drug Metab Pharmacokinet. 1984;9:275-82.
35. Minuesa G, Arimany-Nardi C, Erkizia I, Cedeno S, Molto J, Clotet B, et al. P-glycoprotein (ABCB1) activity decreases raltegravir disposition in primary $\mathrm{CD} 4+\mathrm{P}-$ gphigh cells and correlates with HIV-1 viral load. J Antimicrob Chemother. 2016;71:2782-92.

36. Hashiguchi Y, Hamada A, Shinohara T, Tsuchiya K, Jono H, Saito $\mathrm{H}$. Role of P-glycoprotein in the efflux of raltegravir from human intestinal cells and CD4+ T-cells as an interaction target for anti-HIV agents. Biochem Biophys Res Commun. 2013;439:221-7.

37. Cattaneo D, Baldelli S, Cerea M, Landonio S, Meraviglia P, Simioni E, et al. Comparison of the in vivo pharmacokinetics and in vitro dissolution of raltegravir in HIV patients receiving the drug by swallowing or by chewing. Antimicrob Agents Chemother. 2012;56:6132-6.

38. Markowitz M, Morales-Ramirez JO, Nguyen BY, Kovacs CM, Steigbigel RT, Cooper DA, et al. Antiretroviral activity, pharmacokinetics, and tolerability of MK-0518, a novel inhibitor of HIV-1 integrase, dosed as monotherapy for 10 days in treatmentnaive HIV-1-infected individuals. J Acquir Immune Defic Syndr. 2006;43:509-15.

39. Barau C, Furlan V, Yazdanpanah Y, Fagard C, Molina JM, Taburet AM, et al. Characterization of binding of raltegravir to plasma proteins. Antimicrob Agents Chemother. 2013;57:5147-50

40. Mahat MY, Thippeswamy BS, Khan FR, Edunuri R, Nidhyanandan S, Chaudhary S. Pregnancy influences the plasma pharmacokinetics but not the cerebrospinal fluid pharmacokinetics of raltegravir: a preclinical investigation. Eur J Pharm Sci. 2014;65:38-44.

41. Wenning LA, Petry AS, Kost JT, Jin B, Breidinger SA, DeLepeleire I, et al. Pharmacokinetics of raltegravir in individuals with UGT1A1 polymorphisms. Clin Pharmacol Ther. 2009;85:623-7.

42. Kassahun K, McIntosh I, Cui D, Hreniuk D, Merschman S, Lasseter K, et al. Metabolism and disposition in humans of raltegravir (MK-0518), an anti-AIDS drug targeting the human immunodeficiency virus 1 integrase enzyme. Drug Metab Dispos. 2007;35:1657-63.

43. Usui $T$, Kuno T, Mizutani T. Induction of human UDP-glucuronosyltransferase $1 \mathrm{~A} 1$ by cortisol-GR. Mol Biol Rep. 2006;33:91-6.

44. Eron JJ Jr, Rockstroh JK, Reynes J, Andrade-Villanueva J, Ramalho-Madruga JV, Bekker LG, et al. Raltegravir once daily or twice daily in previously untreated patients with HIV-1: a randomised, active-controlled, phase 3 non-inferiority trial. Lancet Infect Dis. 2011;11:907-15.

45. Rizk ML, Hang Y, Luo WL, Su J, Zhao J, Campbell H, et al. Pharmacokinetics and pharmacodynamics of once-daily versus twice-daily raltegravir in treatment-naive HIV-infected patients. Antimicrob Agents Chemother. 2012;56:3101-6.

46. Garrido C, de Mendoza C, Alvarez E, Garcia F, Morello J, Garcia $\mathrm{S}$, et al. Plasma raltegravir exposure influences the antiviral activity and selection of resistance mutations. AIDS Res Hum Retroviruses. 2012;28:156-64.

47. Krishna R, Rizk ML, Larson P, Schulz V, Kesisoglou F, Pop R. Single- and multiple-dose pharmacokinetics of once-daily formulations of raltegravir. Clin Pharmacol Drug Dev. 2018;7(2):196-206.

48. Marzolini C, Decosterd L, Winterfeld U, Tissot F, Francini K, Buclin $\mathrm{T}$, et al. Free and total plasma concentrations of elvitegravir/cobicistat during pregnancy and postpartum: a case report. Br J Clin Pharmacol. 2017;83:2835-8.

49. Schalkwijk S, Colbers A, Konopnicki D, Greupink R, Russel FG, Burger D, et al. First reported use of elvitegravir and cobicistat during pregnancy. AIDS. 2016;30:807-8. 
50. Truong WR, Schafer JJ, Short WR. Once-daily, single-tablet regimens for the treatment of HIV-1 infection. $\mathrm{P} T$. 2015;40:44-55.

51. Ramanathan S, Mathias AA, German P, Kearney BP. Clinical pharmacokinetic and pharmacodynamic profile of the HIV integrase inhibitor elvitegravir. Clin Pharmacokinet. 2011;50:229-44.

52. Gilead. Highlights of prescribing information Vitekta (elvitegravir) tablets, for oral use. http://gilead.com/ /media/files/pdfs/ medicines/hiv/vitekta/vitekta_pi.pdf?la=en. Accessed 29 Sept 2017.

53. Xu L, Liu H, Murray BP, Callebaut C, Lee MS, Hong A, et al. Cobicistat (GS-9350): a potent and selective inhibitor of human CYP3A as a novel pharmacoenhancer. ACS Med Chem Lett. 2010;1:209-13.

54. Wang P, Shehu AI, Liu K, Lu J, Ma X. Biotransformation of cobicistat: metabolic pathways and enzymes. Drug Metab Lett. 2016;10:111-23.

55. Farooq M, Kelly EJ, Unadkat JD. CYP2D6 is inducible by endogenous and exogenous corticosteroids. Drug Metab Dispos. 2016;44:750-7.

56. Ke AB, Nallani SC, Zhao P, Rostami-Hodjegan A, Isoherranen $\mathrm{N}$, Unadkat JD. A physiologically based pharmacokinetic model to predict disposition of CYP2D6 and CYP1A2 metabolized drugs in pregnant women. Drug Metab Dispos. 2013;41:801-13.

57. German P, Warren D, West S, Hui J, Kearney BP. Pharmacokinetics and bioavailability of an integrase and novel pharmacoenhancer-containing single-tablet fixed-dose combination regimen for the treatment of HIV. J Acquir Immune Defic Syndr. 2010;55:323-9.

58. DeJesus E, Berger D, Markowitz M, Cohen C, Hawkins T, Ruane $\mathrm{P}$, et al. Antiviral activity, pharmacokinetics, and dose response of the HIV-1 integrase inhibitor GS-9137 (JTK-303) in treatmentnaive and treatment-experienced patients. J Acquir Immune Defic Syndr. 2006;43:1-5.

59. Bollen PD. A comparison of the pharmacokinetics of dolutegravir in pregnancy and postpartum. Abstract submitted to the 18th international workshop on clinical pharmacology of antiviral therapy [Oral abstract 0_7]. http://www.thebodypro.com/content/ 80143/dolutegravir-pharmacokinetics-in-pregnancy.html. Accessed 1 Nov 2017.

60. Waitt C, Walimbwa S, Orrell C, Lamorde M, Heiberg C, Mehta U, et al. DolPHIN-1: dolutegravir versus efavirenz when initiating treatment in late pregnancy. 2018. http://www. croiconference.org/sessions/dolphin-1-dolutegravir-vs-efavirenzwhen-initiating-treatment-late-pregnancy.

61. Schalkwijk S, Feiterna-Sperling C, Weizsacker K, Colbers A, Buhrer C, Greupink R, et al. Substantially lowered dolutegravir exposure in a treatment-experienced perinatally HIV-1-infected pregnant woman. AIDS. 2016;30:1999-2001.

62. van Lunzen J, Maggiolo F, Arribas JR, Rakhmanova A, Yeni P, Young B, et al. Once daily dolutegravir (S/GSK1349572) in combination therapy in antiretroviral-naive adults with HIV: planned interim 48 week results from SPRING-1, a dose-ranging, randomised, phase 2b trial. Lancet Infect Dis. 2012;12:111-8.

63. Kobayashi M, Yoshinaga T, Seki T, Wakasa-Morimoto C, Brown $\mathrm{KW}$, Ferris R, et al. In Vitro antiretroviral properties of S/GSK1349572, a next-generation HIV integrase inhibitor. Antimicrob Agents Chemother. 2011;55:813-21.

64. Castellino S, Moss L, Wagner D, Borland J, Song I, Chen S, et al. Metabolism, excretion, and mass balance of the HIV-1 integrase inhibitor dolutegravir in humans. Antimicrob Agents Chemother. 2013;57:3536-46.

65. Reese MJ, Savina PM, Generaux GT, Tracey H, Humphreys JE, Kanaoka E, et al. In vitro investigations into the roles of drug transporters and metabolizing enzymes in the disposition and drug interactions of dolutegravir, a HIV integrase inhibitor. Drug Metab Dispos. 2013;41:353-61.

66. Choi SY, Koh KH, Jeong $\mathrm{H}$. Isoform-specific regulation of cytochromes $\mathrm{P} 450$ expression by estradiol and progesterone. Drug Metab Dispos. 2013;41:263-9.

67. Cheung NW, Liddle C, Coverdale S, Lou JC, Boyages SC. Growth hormone treatment increases cytochrome P450-mediated antipyrine clearance in man. J Clin Endocrinol Metab. 1996;81:1999-2001.

68. Zhang J, Hayes S, Sadler BM, Minto I, Brandt J, Piscitelli S, et al. Population pharmacokinetics of dolutegravir in HIV-infected treatment-naive patients. Br J Clin Pharmacol. 2015;80:502-14.

69. Cottrell ML, Hadzic T, Kashuba AD. Clinical pharmacokinetic, pharmacodynamic and drug-interaction profile of the integrase inhibitor dolutegravir. Clin Pharmacokinet. 2013;52:981-94.

70. Min S, Sloan L, DeJesus E, Hawkins T, McCurdy L, Song I, et al. Antiviral activity, safety, and pharmacokinetics/pharmacodynamics of dolutegravir as 10-day monotherapy in HIV-1-infected adults. AIDS. 2011;25:1737-45.

71. Wainberg MA, Friedland G. Public health implications of antiretroviral therapy and HIV drug resistance. JAMA. 1998;279:1977-83.

72. Farnsworth A, Dumestre J, Acosta E, Howels A, Merideth G, Schmitt J. Use of medication management tools to increase adherence in a controlled trial of quadruple-drug therapy in HIV positive female patients [abstract no. 32364 2000]. 12th World Aids Conference; 28 June-3 July 1998: Geneva.

73. Trezza C, Ford SL, Spreen W, Pan R, Piscitelli S. Formulation and pharmacology of long-acting cabotegravir. Curr Opin HIV AIDS. 2015;10:239-45.

74. Bowers GD, Culp A, Reese MJ, Tabolt G, Moss L, Piscitelli S, et al. Disposition and metabolism of cabotegravir: a comparison of biotransformation and excretion between different species and routes of administration in humans. Xenobiotica. 2016;46:147-62.

75. Cho SJ, Ning M, Zhang Y, Rubin LH, Jeong H. 17beta-Estradiol up-regulates UDP-glucuronosyltransferase $1 \mathrm{~A} 9$ expression via estrogen receptor alpha. Acta Pharm Sin B. 2016;6:504-9.

76. Miners JO, Robson RA, Birkett DJ. Paracetamol metabolism in pregnancy. Br J Clin Pharmacol. 1986;22:359-62.

77. Beaulac-Baillargeon L, Rocheleau S. Paracetamol pharmacokinetics during the first trimester of human pregnancy. Eur J Clin Pharmacol. 1994;46:451-4.

78. Kulo A, Peeters MY, Allegaert K, Smits A, de Hoon J, Verbesselt $\mathrm{R}$, et al. Pharmacokinetics of paracetamol and its metabolites in women at delivery and post-partum. $\mathrm{Br} \mathrm{J}$ Clin Pharmacol. 2013;75:850-60.

79. Margolis DA, Gonzalez-Garcia J, Stellbrink HJ, Eron JJ, Yazdanpanah Y, Podzamczer D, et al. Long-acting intramuscular cabotegravir and rilpivirine in adults with HIV-1 infection (LATTE-2): 96-week results of a randomised, open-label, phase 2b, non-inferiority trial. Lancet. 2017;390:1499-510.

80. Lazerwith SE. Discovery of bictegravir (GS-9883), a novel, unboosted, once-daily HIV-1 integrase strand transfer inhibitor (INSTI) with improved pharmacokinetics and in vitro resistance profile presented at the ASM microbe; 16-20 June 2016: Boston, MA. http://www.natap.org/2016/HIV/062016_05.htm. Accessed 10 Jan 2018.

81. Zhang H. Clinical pharmacology of the unboosted HIV integrase strand transfer inhibitor (INSTI) bictegravir (BIC) [abstract number 40]. Presented at the Conference on Retroviruses and Opportunistic Infections (CROI); 13-16 Feb 2017: Seattle, WA. http://www.croiconference.org/sessions/clinical-pharmacologyhiv-integrase-strand-transfer-inhibitor-bictegravir. Accessed 10 Jan 2018. 
82. Gallant J. Novel integrase strand transfer inhibitor bictegravir 10 day monotherapy in HIV-1-infected patients [poster number P-18]. Poster presented at the Netherlands Conference on HIV 2016; 22 November 2016: Amsterdam. http://nchiv.org/wpcontent/uploads/2016/12/18_Pistoor.pdf. Accessed 10 Jan 2018.

83. Chen S, Yueh MF, Evans RM, Tukey RH. Pregnane-x-receptor controls hepatic glucuronidation during pregnancy and neonatal development in humanized UGT1 mice. Hepatology. 2012;56:658-67.

84. Zembruski NC, Buchel G, Jodicke L, Herzog M, Haefeli WE, Weiss J. Potential of novel antiretrovirals to modulate expression and function of drug transporters in vitro. J Antimicrob Chemother. 2011;66:802-12.

85. Tsuchiya K, Hayashida T, Hamada A, Oki S, Oka S, Gatanaga H. High plasma concentrations of dolutegravir in patients with ABCG2 genetic variants. Pharmacogenet Genom. 2017;27:416-9.

86. Reese MJ, Bowers GD, Humphreys JE, Gould EP, Ford SL, Webster LO, et al. Drug interaction profile of the HIV integrase inhibitor cabotegravir: assessment from in vitro studies and a clinical investigation with midazolam. Xenobiotica. 2016;46:445-56.

87. Lepist EI, Phan TK, Roy A, Tong L, Maclennan K, Murray B, et al. Cobicistat boosts the intestinal absorption of transport substrates, including HIV protease inhibitors and GS-7340, in vitro. Antimicrob Agents Chemother. 2012;56:5409-13.

88. Yeboah D, Sun M, Kingdom J, Baczyk D, Lye SJ, Matthews SG, et al. Expression of breast cancer resistance protein (BCRP/
ABCG2) in human placenta throughout gestation and at term before and after labor. Can J Physiol Pharmacol. 2006;84:1251-8.

89. Whitfield T, Torkington A, van Halsema C. Profile of cabotegravir and its potential in the treatment and prevention of HIV-1 infection: evidence to date. HIV AIDS (Auckl). 2016;8:157-64.

90. Wang L, Soon GH, Seng KY, Li J, Lee E, Yong EL, et al. Pharmacokinetic modeling of plasma and intracellular concentrations of raltegravir in healthy volunteers. Antimicrob Agents Chemother. 2011;55:4090-5.

91. Benet LZ, Hoener BA. Changes in plasma protein binding have little clinical relevance. Clin Pharmacol Ther. 2002;71:115-21.

92. Schalkwijk S, Greupink R, Burger D. Free dug concentrations in pregnancy: Bound to measure unbound? Br J Clin Pharmacol. 2017;83:2595-8.

93. Agnoletto V, Martnin M, Hollander L, Cargnel A, Riva P, Mazzotta F, et al. Qualitative analyses of behaviours related to compliance in HIV treatments [abstract no. 567]. 7th European Conference on Clinical Aspects and Treatment of HIV-Infection; 23-27 Oct 1999: Lisbon.

94. EMA. Stribild: summary of product characteristics. 2018. http:// www.ema.europa.eu/docs/en_GB/document_library/EPAR_-Product_Information/human/002574/WC500144272.pdf. Accessed Apr 2018.

95. Dooley KE, Sayre P, Borland J, Purdy E, Chen S, Song I, et al. Safety, tolerability, and pharmacokinetics of the HIV integrase inhibitor dolutegravir given twice daily with rifampin or once daily with rifabutin: results of a phase 1 study among healthy subjects. J Acquir Immune Defic Syndr. 2013;62:21-7. 